\title{
Investment attractiveness of enterprise and sustainable development of industrial region
}

\author{
Gennady Alexandrov ${ }^{1}$ and Galina Skvortsova ${ }^{1, *}$ \\ ${ }^{1}$ Tver State Technical University, Tver, Russia
}

\begin{abstract}
In accordance with the Russian Federation consistent transition to sustainable development, which material basis consists in not so much quantitative but rather qualitative transformations in the factors of real economy production, the authors hereby focus on the regional aspect of territorial entity environments affecting favorably the investment attractiveness of industrial enterprises. Special attention is paid to the fact that following the sustainable development paradigm implies a balanced solution of economic, social and environmental problems. The conceptual considerations presented are taken as the basis for an original universal method to diagnose and assess restrictions, threats, and challenges of an economic, administrative and legal, resource and technical, social and environmental nature that occur at the regional level and affect the investment attractiveness of enterprises. In practice, the approach considers the diagnostics possibility to develop, firstly, specific measures to offset or reduce the negative impacts determining the investment attractiveness of regional investment objects and, secondly, motivational and stimulating measures to resolve the conflicts arising due to environmental and social restrictions on economic activity in order to ensure, as we move towards sustainable development, a balanced solution to three tasks: ensuring economic growth, achieving social progress, and improving the quality of the environment.
\end{abstract}

\section{Introduction}

Since the 1980s researchers have been actively discussing the problems of assessing the economic impact of environmental, social and political problems and the risks of largescale migration and conflicts [1]. Special attention is paid to social policy and the level of the quality of a nation's life $[2,3]$. The researches claim that tangible and intangible resources should be used to make the life of mankind as safe and comfortable as possible. At the same time, they note that the analysis of the interdependence of natural resource scarcity and sustainable economic development shows that the scarcity of resources provokes fear which can undermine well-being [3]. Moreover, some authors believe, "The components of social fears have become an integral part of human existence" [4] and suggest considering nontraditional factors such as investors' sentiment and taking into account the components of social fears [5].

\footnotetext{
${ }^{*}$ Corresponding author: gala-skvortsova@yandex.ru
} 
In fact, it was the need to maintain a balance between solving economic and social problems as well as problems of preserving the environment that led to the development of the Concept of Sustainable Development. To balance economic growth, social progress and quality of the environment, i.e. all subsystems including territories, in the sustainable development model is quite difficult. Each of the subsystems can develop in opposite directions and manifest itself in different ways depending on the industry and geography. However, the World Investment Report 2020 declares that the progress of investing in sustainable development requires not only fund raising but also sound environmental, social and managerial practices in enterprise activities to ensure a positive revenue on investment.

As for investing in Russian enterprises, it is necessary to develop and implement programs to transit to sustainable development for each region and to focus on the relevant priorities in economic, social, and environmental spheres. First of all, attention is paid to the fact that optimal investment decisions should be made due to the risks generated by the introduction of reasonable environmental and social restrictions on economic activities of business structures. However, the development and implementation of regional investment policy should take into account that risks and restrictions can have a very negative impact on enterprise investment attractiveness in the region and, thereafter, on business investment motivation. In this regard, the authors pay special attention that mutually beneficial decisions should be made to resolve objective contradictions in relations between the region with its need for sustainable development and investors' economic interests.

\section{Purpose of the Study}

The purpose of the study is, firstly, to assess the investment effects on the balanced sustainable territory development, with economic and financial objectives being consistent with environmental and social processes, and, secondly, to develop a methodology and a specific method to diagnose and assess the interdependence in order to introduce institutional measures to take adequate investment decisions on the regional sustainable development. The implementation is determined by the complexity and difficulty of the concept application that has been emphasized from the very beginning of the discussion about the necessity of sustainable development transition. This fact proves the need for a conceptual solution to the problem of balancing economic growth, making steady social progress, and improving the quality of the environment. This is particularly important because the principles of sustainable development are being criticized by, for example, D. Chandler who states that universal declarations on the priority of human rights and interests, human security or human development represent a kind of international domination of economically developed countries, the institutionalization of market inequality or the restoration of traditional hierarchies of power reminiscent of the colonial era [6].

\section{Literature Review and Hypothesis Development}

A hypothesis for targeting investments on the territory transition to sustainable development and a specific method for diagnosing and assessing regional factors determining the investment attractiveness of enterprises are suggested with a review of the current concept of sustainable development presented in scientific publications. The World Investment Report 2020 states that since the development of any economic system is determined by the volume and structure of investments, the last decade has seen a sharp increase in sustainability initiatives, in particular, in the creation of various sustainable investment funds pursuing, along with economic ones, the goals of obtaining 
environmental, social, and managerial results. Investments to use production factors, resources, and cheap labor, i.e. extensive investments, has underpinned the development strategies of many countries over the past three decades. Moreover, as the Report notes, the economic growth in rich countries as a mechanism to solve the problem may not work because, as it has become particularly clear, the true limits of the humanity's material growth today are determined not so much by physical reasons but by environmental, biological, and even cultural and psychological ones.

Besides, an additional impetus is given by the globalization factor affecting ambiguously the implementation of the advanced development concept. Firstly, the publications note that the influence is different in countries with different globalization levels. The KOF Globalization Index is a composite index of the KOF Swiss Economic Institute, which measures globalization degree for a country in the world. The index value divides countries into countries with a high degree of globalization and countries with a low degree of globalization in accordance with their rating of the world's globalization [7]. Secondly, experience has shown that financial crises in countries with different globalization degrees affect their economic growth in different ways [8]. Economically developed countries tend to be more open and integrated into the world. However, they may also experience a decline in their production growth, as globalization is not unlimited. The globalization of low-income countries brings both benefits and losses, which has an ambiguous effect on entrepreneurs' motivation to invest and determines the movement towards sustainable development. Nevertheless, everything, eventually, depends on the country's objective situation and a territory as well as on who the subject of the assessment is.

Meanwhile, the analysis of investing sustainable development in different economies shows an ambiguous and contradictory situation with both domestic and foreign investments. For example, the last decade has seen a sluggish growth of international investment. At the same time, there is a forecast that "investments in developing countries will suffer greatly since those in export-oriented and raw material production, in particular, will be most affected" (World Investment Report 2020). Such a very negative trend may develop into a long-term problem especially acute for developing countries. The US researchers [9] argue that increased public investment in commodity exporting countries can boost growth, but too fast budgetary spending increases macroeconomic vulnerability. At the same time, some articles have analyzed and noted $[10,11]$ that the effects of investment of the revenues derived from natural resources point to the conclusion that public investment is ineffective. As for foreign investment inflows, they are negatively affected by the uncertainties caused by the country's domestic economic policy [12]. However, business focused on technical efficiency, as, for example, Taiwanese researchers consider, correlates positively with the activities in the field of foreign investment inflows [13]. In addition, some analysts confirm that the less dependence on raw material export contributes to the more significant role of foreign direct investment in reviving the economic growth dynamics [14]. By the way, it is important to note that in moving to sustainable development the social return on direct investment inflows is much greater than on domestic ones [15].

Thus, as follows from the above, the publications on investment for sustainable development and in the age of globalization consider investments and investment processes not only in the view of financial models calculating returns on invested capital but also in the view of environmental, social, administrative and legal (managerial) factors. In particular, nonfinancial attributes are believed to have greater influence on investments (investment processes) [16].

To address the global challenges of sustainable development radical approaches are required. Economic growth is not the best mechanism for improving people's lives because 
"growth alone cannot do it." Growth and development are not the words of the same content and they do not mean the same thing. Growth means more and development means better. Let us ask ourselves whether the opposition between economic growth and economic development is justified, whereas classical economic theory dating back to the time of A. Smith and D. Ricardo and then K. Marx has distinguished between the concepts of simple and extended reproduction. Besides, extended reproduction was characterized as extensive, i.e. carried out by expanding "the field of production", and intensive if "more efficient means of production are used." The same applies to the differentiation of economic growth types. Therefore, it would be theoretically correct not to contrast sustainable development with economic growth but to consider sustainable economic growth in the case of expanded reproduction on an innovative basis. In other words, it is quite possible to achieve both more and better in the context of economic growth.

Thus, the situation with the transition to sustainable development including that at the territorial (regional) level determines the content of the proposed hypothesis suggesting that the nature of investment processes should correspond to the goals of sustainable development. However, this correspondence can be ensured only if the region itself is attractive for investment, which is equivalent to creating an environment where specific investment objects are investment-friendly. Hence, the most important thing is to create of provide favourable conditions in the regions, firstly, to attract investment for sustainable development, and secondly, to remove barriers and restrictions, threats and challenges affecting negatively investment attractiveness of enterprises. However, the hypothesis proposed has an objective contradiction consisting in the fact that the conditions of transition to sustainable development can be factors, on the one hand, limiting investment activities and, on the other hand, being introduced as investment restrictions to solve environmental and social problems. In the latter case, the hypothesis provides for the possibility to resolve the contradiction by developing adequate measures of an organizational and economic nature and introducing them in economic policy implemented at the appropriate levels of the economic hierarchy.

\section{Results}

To identify the factors having a negative impact on sustainable investment effectiveness the authors has developed a methodological approach based on the principle of "levelsfactors" [17]. The principle provides a new way to diagnose and assess the factors characterizing the investment climate in the region and the investment attractiveness of its enterprises. It involves a complex assessment of specific group factors formed not only directly at the level of enterprises themselves but also on upper hierarchical levels (Table 1). This means that the object of the analysis is a group of external environmental factors manifesting themselves as barriers and restrictions at the sectoral, territorial (regional) and, in general, national levels. To support the proposed hypothesis, the authors, focus initially on the principles of grouping factors, then identify and group the specific factors being selected because of the highest, compared to other factors, influence on the investment climate in the region and on the nature of the region progress to sustainable development. Further, the factors are assessed as substances of aggregated unsystematical risk components taken into account in making investment decisions focused on sustainable development.

We work by the theoretical proposition that, first of all, the production process is based on the interaction of material and personal factors, is provided by conditions of production (infrastructure) being a unity of productive forces (means of labor and conditions of production such as organizational, social and environmental, labor force) and corresponding industrial relations. Secondly, the principle of grouping factors that 
determine investment attractiveness is based on the fact that a production process is characterized by certain organizational, economic, and legal relations as well as social and environmental aspects.

Table 1. The matrix, based on the principle of "levels-factors" (Source: Authoring).

\begin{tabular}{|c|c|c|c|c|c|}
\hline $\begin{array}{l}\text { Group of } \\
\text { Factors (F) }\end{array}$ & $\begin{array}{l}\text { Economic } \\
\text { (E) }\end{array}$ & $\begin{array}{l}\text { Administrative } \\
\text { and legal } \\
\text { (A) }\end{array}$ & $\begin{array}{l}\text { Resource } \\
\text { and } \\
\text { technical } \\
\text { (T) }\end{array}$ & $\begin{array}{c}\text { Social and } \\
\text { environmental } \\
\text { (S) }\end{array}$ & $\begin{array}{c}\text { Sum of } \\
\text { estimation } \\
\text { by levels } \\
\left.\text { (Sum }_{L}\right)\end{array}$ \\
\hline $\begin{array}{l}\text { National } \\
\text { economy (N) }\end{array}$ & $N-E$ & $\mathrm{~N}-\mathrm{A}$ & $\mathrm{N}-\mathrm{T}$ & $\mathrm{N}-\mathrm{S}$ & $\operatorname{Sum}_{N}$ \\
\hline $\begin{array}{l}\text { Region } \\
\text { (R) }\end{array}$ & $R-E$ & R- A & $\mathrm{R}-\mathrm{T}$ & $\mathrm{R}-\mathrm{S}$ & Sum $_{R}$ \\
\hline $\begin{array}{l}\text { Industry } \\
\text { (I) }\end{array}$ & I - E & $\mathrm{I}-\mathrm{A}$ & $\mathrm{I}-\mathrm{T}$ & $I-S$ & SumI \\
\hline $\begin{array}{l}\text { Enterprise } \\
\text { (En) }\end{array}$ & En- E & En -A & En - T & En $-\mathrm{S}$ & SumEn \\
\hline $\begin{array}{l}\text { Sum of } \\
\text { estimation } \\
\text { by group of } \\
\text { factors } \\
(\text { SumF }) \\
\end{array}$ & Sum $_{E}$ & $\operatorname{Sum}_{A}$ & $\operatorname{Sum}_{T}$ & Sums $_{S}$ & $\begin{array}{l}\operatorname{Sum}_{F}= \\
\operatorname{Sum}_{L}\end{array}$ \\
\hline
\end{tabular}

Therefore, it would be quite appropriate to form the following four main groups of factors: economic, administrative and legal, resource and technical, and social and environmental. The "level-factor approach" (see the Table 1) should provide an opportunity to analyze and assess investment attractiveness so that, firstly, a potential investor having the diagnostics results can make a reasoned decision about investing; secondly, an invested entrepreneur can get a real idea of the factors and trends affecting negatively their business investment attractiveness; thirdly, all those who somehow manage the investment climate at their own level (including the invested entrepreneur) could decide on measures that would help to eliminate everything that negatively affects its attractiveness. To carry out the tasks mentioned above, we propose a step-by-step algorithm for diagnosing and assessing the regional environment which determines the attractiveness of enterprises operating on its territory.

STEP 1. Identify possible factors and group them into your specific group and the corresponding hierarchical level.

Considering the nature of the problems under discussion as well as the limited size of the article, the authors focus their attention on the band "a region - a group of social and economic factors." The reason is the fact that a social and economic direction, on the one hand, is becoming increasingly important since sustainable development requires that the quality of environment and life activity, social equality of people play a significant role, and consequently, the role of corporate social and environmental responsibility as a standard of doing business is increasing. Therefore, investment processes determining development cannot be considered in isolation from, firstly, the extent to which investment in development meets the requirements of social progress, secondly, the effective use of natural resources, and thirdly, the requirements of environmental protection. At the same time, it should be taken into account that a comprehensive assessment of the investment attractiveness of specific investment objects should be done with the diagnostics of all the factors shaping the investment climate at all levels of management hierarchy since all four groups of factors are in some respect interrelated. 
A group of social and environmental factors is associated with a group of administrative and legal factors. These factors are: a social and political situation in the region; the authorities' willingness to reform it; the degree of the regional authorities' independence in making decisions to motivate and stimulate social and environmental policies. The administrative and legal factors listed here, that characterize the investment climate of the region, in certain conditions, can become significant barriers and restrictions for investors determining the possibility of their entry into the region.

Social factors and their influence on the investment attractiveness of the regions and the enterprises operating there are connected with environmental factors. This relationship is clearly seen in the fact that the environmental deterioration results in some social problems having a negative impact on the people's living conditions. Besides, the lack of research on the topic becomes an obstacle to developing effective mechanisms for their solution.

The factors making up a social and ecological group and emerging at the regional level are, in general, identified as: the quality of life; the social status of the population; the condition of demography and migration; the availability of necessary social infrastructure; social stability; the environmental status. They also include the ability of the region to solve nature and environmental protection problems independently.

STEP 2. Recognize the regional factors having a decisive influence on the investment attractiveness of enterprises; take into account the need to achieve the sustainable development goals.

At the beginning of diagnosing by the expert method all factors considered receive a score, which further allow them to be ranked according to the degree of their influence on the attractiveness of a particular investment object. The results of factor ranking and V. Pareto principle help select from an array of assessed factors $20 \%$ of those determining $80 \%$ of the investment attractiveness of the whole region and specific investment object in the band "a region - a group of social and economic factors."

STEP 3. Assess individual factors and the whole group of social and environmental factors at this hierarchical level in the form of an unsystematical component of the aggregated regional risk.

The assessment, together with systematic risk, can be used as a discount rate in justifying the feasibility of investment decisions. It should be taken into account that the third step faces the challenge of switching from the factor scores obtained through their diagnostics to the corresponding risks. Essentially, the challenge results from summing up the summands: a systematical component obtained by the calculation method, and an unsystematical component determined by expert evaluation. A relatively simple methodological approach is proposed to provide an assessment of an unsystematical component of investment risk regardless of the number of factors and the size of the score estimates. Since the article does not offer an example of calculation and only describe the essence of its methodology to solve the problem of assessing unsystematical risk with a coefficient expressing the average ratio of both parts of the risk. The unsystematical component of the investment risk is determined by multiplying the calculated value of the systematical risk by a specified coefficient (see the figure in [17]) and, hence, solving the additivity problem.

STEP 4. Develop specific adequate measures and, correspondingly, ways to take them through creating and reforming certain organizational and economic forms, institutions (adequate to objective economic relations), and developing regulatory mechanisms.

It should be taken into account that the implementation of sustainable development imposes on business and, therefore, investors the requirements of a social and environmental nature, which, as has been mentioned above, may conflict with the interests of the latter and undermine their motivation to invest. Nevertheless, in order to reduce or eliminate barrier and restrictive factors, threats and challenges, the regional capabilities to 
solve these problems may be limited in some cases. However, they can always be solved at the federal level. This applies, first of all, to environmental protection measures and the regional social infrastructure being the objects of lawmaking and economic policy exclusively at the federal level.

\section{Conclusion}

The article has dealt with the thorny theoretical and methodological issues of regional transition to sustainable development through the intensification of investment processes and the creation of a regional environment ensuring an increase in the investment attractiveness of initial investment objects, enterprises. A number of approaches have been proposed for diagnosing the investment attractiveness of enterprises and its subsequent assessment as an unsystematical component of investment risk. They provide greater validity, relevance and reliability of the assessments allowing entrepreneurs to justify and make adequate management decisions in their investment activities taking into account the need to achieve the sustainable development goals. The authors hope that the results of the research presented in the article will allow us,

firstly, to see with greater breadth and deeper understanding the methodological approaches to determining the specific factors characterizing the investment climate of regions and the investment attractiveness of enterprises;

secondly, to focus on social and environmental factors as the basis to form an appropriate component of unsystematical investment risk;

thirdly, to determine the areas where it is necessary to develop specific measures to eliminate or minimize specific factors having a negative impact on the investment attractiveness of investment objects. Ultimately, the introduction of the measures should contribute to investment process intensification and ensure the regional transition to sustainable development.

\section{Acknowledgment}

The reported study was funded by RFBR, project number 20-010-00124.

\section{References}

1. N. Stern, Journal of Economic Literature 51(3), 838-859 (2013) DOI: https://doi.org/10.1257/jel.51.3.838

2. I. Selahattin, S. Kitao, American Economic Journal: Macroeconomics 4(3), 96-127 (2012) DOI: https://doi.org/10.1257/mac.4.3.96

3. L.H. Endress, Scarcity, Security, and Sustainable Development. In: Sustainable Economic Development. Resources, Environment and Institutions (Academic Press, 2015) DOI: https://doi.org/10.1016/B978-0-12-800347-3.00003-0

4. A.M. Rudenko, V.I. Rodionova, V.N. Stepanova, Advances in Intelligent Systems and Computing 726, 1144-1155 (2019) DOI: 10.1007/978-3-319-90835-9_129

5. K. Solanki. Y. Seetharam, Investment Analysts Journal 47, 243-257 (2018) DOI: https://doi.org/10.1080/10293523.2018.1497250

6. D. Chandler, International Journal of Security and Development 4(1), 1-14 (2015) DOI: https://doi.org/10.5334/sta.fb 
7. P.H. Leal, A.C. Marques, International Economics 164, 36-47 (2020) DOI: 10.1016/j.inteco.2020.07.001

8. B. Candelon, A. Carare, J-B. Hasse, J. Lu, International Economics 161, 139-158 (2020) DOI: 10.1016/j.inteco.2019.11.011

9. B. Grace Li, P. Gupta, J.Yu. International Economics 151, 7-25 (2017) DOI: 10.1016/j.inteco.2017.03.001

10. A. Berg, R. Portillo, S.-C.S Yang, L.-F. Zanna, IMF Economic Review 61(1), 92-129 (2013) DOI:10.1057/imfer.2013.1.pdf

11. G. Melina, SCS. Yang, L.F. Zanna, Economic Modelling 52, 630-649 (2016) DOI: https://doi.org/10.1016/j.econmod.2015.10.007

12. N. Phuc Canh, N. Thanh Binh, S. Dinh Thanh, C. Schinckus, International Economics 161, 159-172 (2020) DOI: 10.1016/j.inteco.2019.11.012

13. S.-F. Yang, K.-M. Chen, T.-H. Huang, Journal of Asian Economics 27, 7-17 (2013) DOI:10.1016/j.asieco.2013.04.007

14. A. Mohamed, Foreign Direct Investment in Brazil: Post-Crisis Economic Development in Emerging Markets (Academic Press, 2016) DOI:10.1016/C2014-0-01881-3

15. N. Driffield, The Annals of Regional Science 38(4), 579-594 (2004) DOI:10.1007/s00168-003-0174-5

16. Z. Umar, D. Kenourgios, S. Papathanasiou, Economic Modelling 93, 112-124 (2020) DOI:10.1016/j.econmod.2020.08.007

17. G.A. Alexandrov et al, Attractiveness of the investment climate and investment risks: methodology, diagnostic tools and evaluation methods (Creative Economy, 2020) DOI:10.18334/9785912923050 